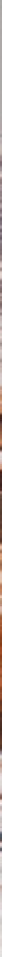

Domestic goats and sheep can graze marginal lands, such as those in the Gobi Desert in Mongolia.

\title{
Steps to sustainable livestock
}

With improved breeding and cultivation, ruminant animals can yield food that is
better for people and the planet, say Mark C. Eisler, Michael R. F. Lee and colleagues.

\section{$\mathrm{T}$} he need for efficient food production has never been greater. One in seven humans is undernourished ${ }^{1}$. Urbanization and biofuel production are reducing land availability, and climate change, lack of water and soil degradation are decreasing harvests. Over the past decade, cereal yields per hectare have fallen in one-quarter of countries. Meanwhile, developing nations and the growing world population are demanding more animal protein.

The increasing consumption of animal protein is generally considered at odds with Earth's ability to feed its people. The 1 billion tonnes of wheat, barley, oats, rye, maize (corn), sorghum and millet poured annually into livestock troughs could feed some 3.5 billion humans. But such reasoning discounts the health benefits of eating modest amounts of meat and the fact that foraging animals can consume foods that humans cannot eat.

Crop and livestock farming complement each other ${ }^{2}$. Half the world's food comes from farms that raise both. Animals pull ploughs and carts, and their manure fertilizes crops, which supply post-harvest residues to livestock. But efforts to maximize yields of milk and meat can disrupt finely balanced systems. The quest for 'intensification' in livestock farming has thundered ahead with little regard for sustainability and overall efficiency (the net amount of food produced in terms of inputs such as land and water). With animal protein set to remain part of the food supply, we must pursue sustainable intensification and figure out how to keep livestock in ways that work best for individuals, communities and the planet.

Almost all of the world's milk and much of its meat come from ruminant (cud-chewing) animals - mostly cows, goats and sheep, but also buffalo, camels, llamas, reindeer and yaks. Here we highlight eight strategies to cut the environmental and economic costs of keeping these animals while boosting net gains for the quantity and quality of the food they produce.

Feed animals less human food. Around $70 \%$ of the grains used by developed countries are fed to animals. Livestock consume an estimated one-third or more of the world's cereal grain, with $40 \%$ of such feed going to ruminants, mainly cattle ${ }^{1}$

Some of this is avoidable. Ruminants graze pastures and can eat hay, silage and highfibre crop residues that are unsuitable for human consumption. Unlike pigs, poultry and humans, ruminants have a series of forestomachs leading to the true stomach. In the forestomachs, the largest of which is the rumen, microbes break down fibrous plant material into usable calories and also provide high-quality microbial protein. Ruminants can graze in marginal areas, such as mountainsides or low-lying wet grasslands. This helps to reserve agricultural fields for growing human food.

Even where large quantities of cereals are consumed by ruminants, up to $60 \%$ of their diet comes from high-fibre feed that humans cannot digest. In the European Union, more than $95 \%$ of milk comes from animals fed on grass, hay and silage, supplemented with cereals. Cattle in New Zealand's exemplary dairy industry obtain $90 \%$ of their overall nutrition by grazing pasture ${ }^{3}$. China's growing dairy industry initially relied on imported grain and high-quality fibre from the Americas. Ongoing research is showing how best to use local crop residues, such as rice straw.

Raise regionally appropriate animals. The lure of high productivity has led to ill-advised schemes to import livestock to places where they are genetically unsuited. Kerala, a state in southern India, is home to the smallest breed 
of cattle in the world. Vechur cows stand at about 90 centimetres tall and make only around 3 litres of milk per day - a dribble compared to the 30 litres per day produced on average by Holsteins, the black-and-white dairy cows of Europe and North America.

Donors, governments and charities aiming to feed whole communities, and to provide income for poor farmers, have imported Holstein breeding stock and semen to Africa and Asia, with progeny now numbering in the millions. But the animals often disappoint. Bred for centuries for maximum milk production in temperate climates, these cows were not selected for fertility or hardiness. They lack resistance to heat, humidity, tropical diseases and parasites, and so must be kept in stalls away from ticks and other disease vectors. Rather than allowing the animals out to pasture, farmers in tropical areas must cut and carry fodder to the animals or purchase expensive, often imported, feed. Even then, the cows produce less than one-third of yields seen in temperate climates and controlled environments. For poor families, a smaller native cow is a better bet than a larger animal that costs more to keep alive and healthy.

Similarly, breeds of cattle usually farmed in the humid tropics of West Africa have developed resistance to the debilitating disease trypanosomiasis over several thousand years of exposure to the tsetse fly that carries it. In the hope of greater profits and wealth, farmers often replace these animals with larger European cattle, or with zebu breeds from areas north of the tsetse belts. The zebu breeds are less resistant to trypanosomiasis, and European cattle have no resistance. The expense of drugs to combat the disease often outweighs the increase in income.

More can and must be done to encourage farmers to realize the advantages of livestock adapted to local areas. Cutting-edge genomics could guide selective breeding to boost production of animals that are already adapted to their climates and resistant to local diseases.

Keep animals healthy. Sick animals can make people sick. In low- and middleincome nations, 13 livestock-related zoonoses (diseases that can infect humans and animals) cause 2.4 billion cases of human illness and 2.2 million deaths each year ${ }^{4}$. Yet human and livestock disease are generally treated as separate problems. Animal management should include measures to contain transmissible diseases, for example, by improving hygiene, quarantining new arrivals on farms and establishing coordinated, sustained surveillance for diseases that cross the boundaries of species or countries.

Mismanagement and poor welfare render animals particularly susceptible to parasites and disease. Many young animals die of disease before they can lactate, reach slaughter weight or reproduce. This lowers yields, increases environmental impacts and decreases farmers' ability to select the best breeding stock. With education and some financial aid, farmers could improve husbandry, and more animals would survive to become productive.

Keeping animals at high densities spreads infectious diseases far and fast. The foot-andmouth virus costs upwards of US $\$ 5$ billion each year in vaccinations and lost production worldwide. A UK epidemic in 2001 resulted in the slaughter of 6 million animals. Bovine

\section{CUD CHEWERS}

Numbers of domesticated ruminant animals are falling in developed countries and rising in developing ones.

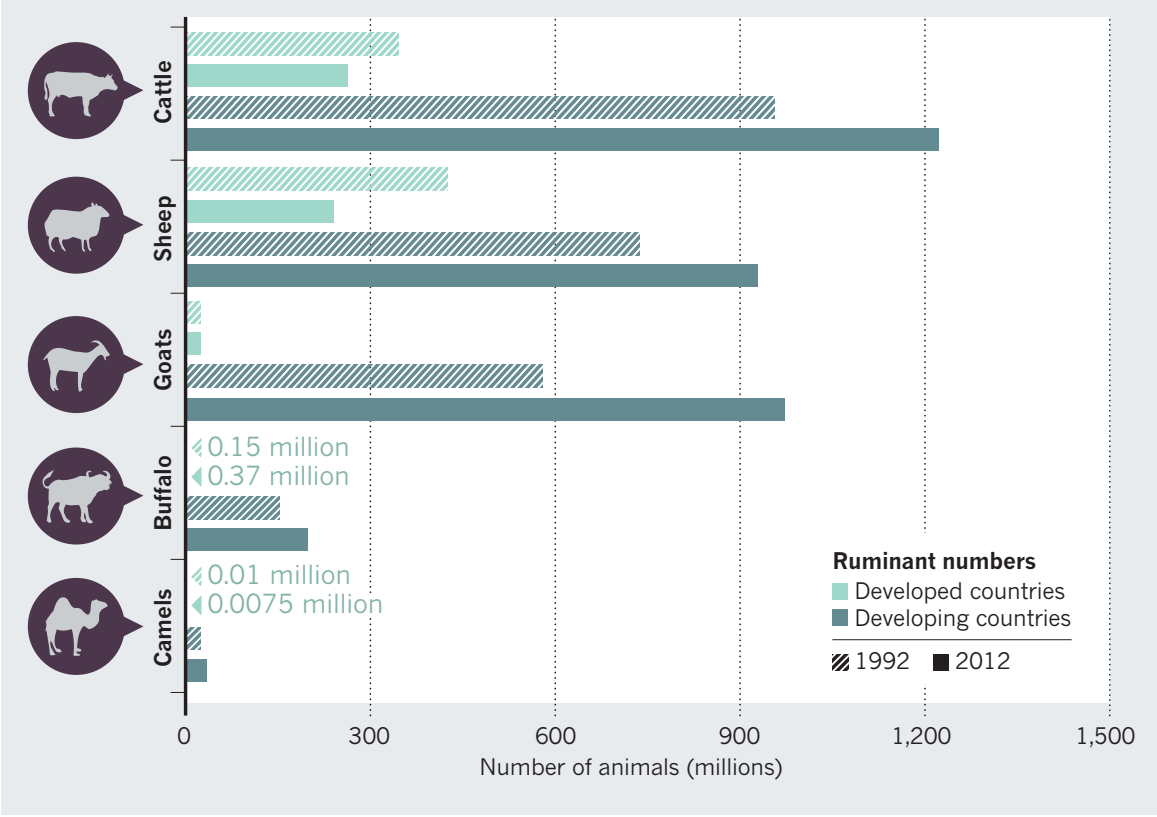

tuberculosis has cost UK taxpayers alone $£ 500$ million (US\$830 million) over the past decade - an amount projected to double in the next ten years. Market disruptions and losses are felt across industries including agriculture, transportation and tourism.

European Union law holds farmers responsible for human health and food-safety issues following the slaughter of their animals. Growing awareness of problems such as antibiotic resistance has led to approaches that rely less on anti-infective drugs and more on management practices, such as reducing

overcrowding. Sim-

"The focus ple decision-support should be on tools are emerging to eating less, better quality meat." help farmers to treat affected individuals rather than entire herds, and to keep animals away from risky pastures or other sources of infection ${ }^{5}$. Gathering local evidence can confirm the benefits of such strategies and encourage farmers to adopt them.

Adopt smart supplements. The productivity of ruminant animals can often be boosted with supplements, some of which encourage microbes in the rumen to grow quickly and to provide better nutrition. In India, a water fern (Azolla caroliniana) cultivated in local ponds provides extra protein to cattle and goats fed on protein-deficient elephant grass (Pennisetum purpureum).

Other plant extracts can alter the rumen microbial population to use nitrogen and energy more efficiently. This means producing more meat and milk with proportionally less by-product greenhouse gas and ammonia. An enzyme in red clover (Trifolium pratense), widely grown in temperate countries, increases ruminants' ability to utilize dietary protein ${ }^{6}$. In field trials, dairy cows with more clover in their diets ate more feed and produced more milk. In Australia, sheep nibble on the deep-rooted perennial tar bush (Eremophila glabra) during dry autumns when most other pasture plants offer poor food value. Tar bush combats gastrointestinal nematodes and acidosis, and reduces emissions of methane, a greenhouse gas 25 times more potent than carbon dioxide.

Governments and policy-makers should support research efforts to identify the most beneficial microbes and most limiting nutrients, as well as low-cost ways to deliver them.

Eat quality not quantity. Annual meat consumption in India is just 3.2 kilograms per person, compared with $125 \mathrm{~kg}$ per person in the United States in 2007, much of it from heavily processed foods, such as burgers, sausages and ready meals. The focus should be on eating less, better quality meat. In rich countries, the high quantity and low quality of processed animal products consumed 

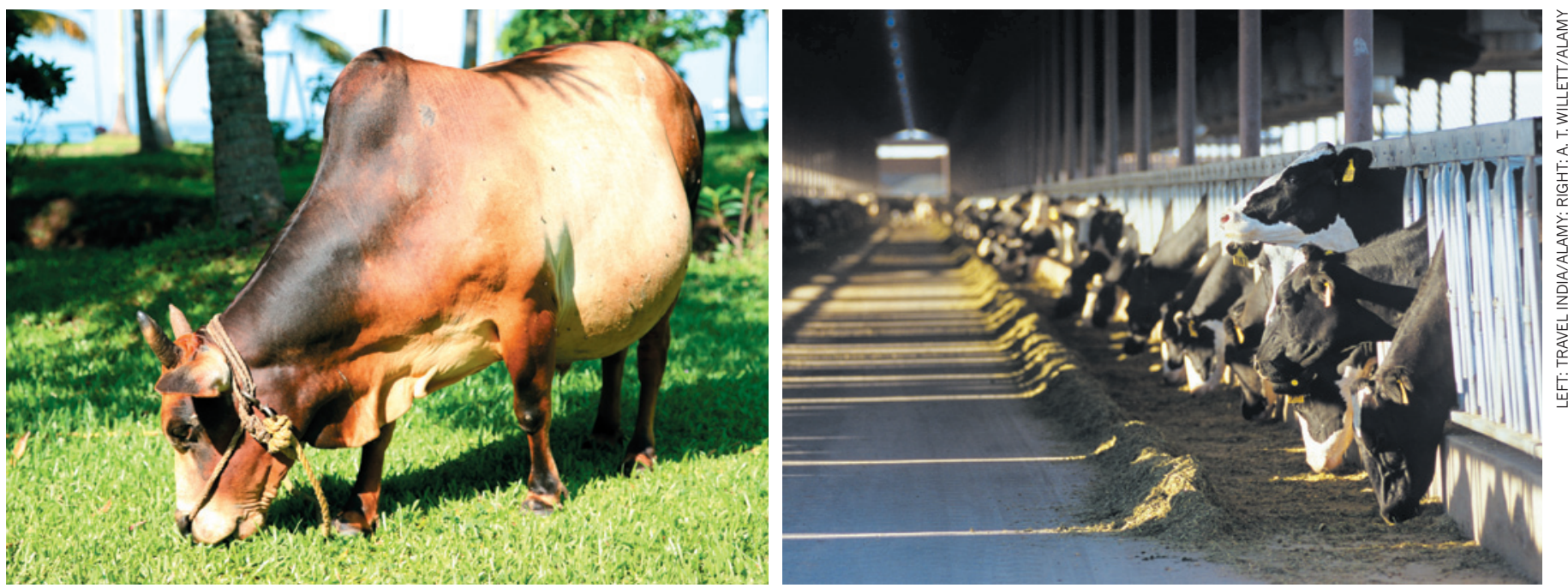

Unlike Vechur cows (left), Holstein cattle (right) have little resistance to heat, humidity and tropical diseases, and are most productive in controlled environments.

contributes to ill health, with higher rates of cancer and coronary heart disease. For the world's poor people, however, there are clear nutritional advantages to consuming small amounts of high-quality animal foods, which are rich in protein, essential amino acids, iron and various essential micronutrients that improve chances for normal physical and cognitive development ${ }^{8}$.

The public-health goal, therefore, should be to balance nutrition across the world, with a target of weekly average consumption of red meat of no more than 300 grams. Trends are in the right direction; numbers of ruminants in the developed world have fallen over the last two decades (see 'Cud chewers').

Tailor practices to local culture. Close to one billion of the world's poorest people rely on livestock for their livelihood. Traditional animal husbandry supplies more than just food ${ }^{9}$. Keeping animals provides wealth, status and even dowry payments. When families encounter large expenses, such as a hospital bill or a wedding, they can sell an animal or two to cover the cost. Many of these benefits are disrupted when conventional grazing and mixed-farming practices are replaced with industrial systems that maximize short-term production. Policies to encourage humane, efficient management should consider cultural as well as natural factors. For instance, in traditional herding communities in the Horn of Africa, philanthropic efforts to support the cattle trade have led to larger herds for wealthier individuals, with little evidence that they have benefited poorer pastoralists.

Track costs and benefits. Livestock are widely considered to be unsustainable. The livestock sector accounts for $14.5 \%$ of human-induced greenhouse-gas emissions, exceeding that from transportation.

However, if other factors are considered, the picture becomes more favourable.
Sustainably managed grazing can increase biodiversity, maintain ecosystem services and improve carbon capture by plants and soil ${ }^{10}$. A cow produces up to $70 \mathrm{~kg}$ of manure per day, providing enough fertilizer in a year for one hectare of wheat, equivalent to $128 \mathrm{~kg}$ of synthetic nitrogen that might otherwise derive from fossil fuels. Mechanized arable agriculture and food processing themselves produce greenhouse gases, and costs of switching are exacerbated if meat's nutritional advantages are considered ${ }^{10}$. Farm animals also provide hides, wool, traction and biogas, a fuel produced from manure.

Calculating how this balances out is hard, but essential. Life-cycle assessment data should be used to tune livestock policies to socioeconomic and geographic environments.

Study best practice. To explore the multidisciplinary strategies described here, we are building a global network of research farms. Three such 'farm platforms' are operational. Two focus on the use of naturally adapted livestock and native plants: the University of Western Australia Future Farm in Pingelly, which has Mediterranean biome conditions and where water conservation is crucial, and the Thiruvazhamkunnu Livestock Research Station in Kerala, India, which has humid tropical conditions and where grazing is strictly limited. At the third, Rothamsted Research North Wyke Farm Platform in Devon, UK, cattle and sheep graze in temperate grassland conditions on three hydrologically isolated, 22-hectare 'farmlets' to compare nutrient cycling and productivity under various pasture-management strategies. There are plans to establish further platforms in South America, North America and China.

There will be no one-size-fits-all solutions. Changing farming practices is difficult, but farm platforms can evaluate potential for increased profits and other benefits, act as examples to follow, and provide information for policy-makers. We hope to identify better practices to optimize the use of livestock in different regions, using local resources, breeds and feedstuffs - and produce tangible evidence to convince local farmers.

Mark C. Eisler is professor of global farm animal health, Michael R. F. Lee is reader in sustainable livestock systems and John F. Tarlton is senior research fellow in matrix biology at the School of Veterinary Sciences, University of Bristol, UK.

Graeme B. Martin is professor of animal science at the UWA Institute of Agriculture, University of Western Australia, Perth, Australia.

John Beddington, Jennifer A. J. Dungait, Henry Greathead, Jianxin Liu, Stephen Mathew, Helen Miller, Tom Misselbrook, Phil Murray, Valil K. Vinod, Robert Van Saun, Michael Winter. e-mail:mark.eisler@bristol.ac.uk

1. Food and Agriculture Organization of the United Nations World Agriculture: Towards 2015/2030 (FAO, 2002).

2. Herrero, M. et al. Science 327, 822-825 (2010).

3. Bocquier, F. \& Gonzalez-Garcia, E. Animal 4, 1258-1273 (2010).

4. Grace, D. et al. Mapping of Poverty and Likely Zoonoses Hotspots (International Livestock Research Institute, 2012).

5. Kenyon, F. et al. Vet. Parasitol. 164, 3-11 (2009).

6. Lee, M. R. F., Tweed, J. K. S., Minchin, F. R. \& Winters, A. L. Anim. Feed Sci. Technol. 149, 250-264 (2009).

7. Bickell, S. L., Durmic, Z., Blache, D., Vercoe, P. E. \& Martin, G. B. in Updates on Ruminant Production and Medicine Proc. 26th World Buiatrics Congress, Santiago, Chile (eds Wittwer, F. et al.) 317-325 (Andros Impresores, 2010).

8. Smith, J. et al. Anim. Front. 3, 6-13 (2013).

9. Otte, J. et al. Livestock Sector Development for Poverty Reduction: An Economic and Policy Perspective - Livestock's Many Virtues (FAO, 2012).

10.Garnett, T. Environ. Sci. Policy 12, 491-503 (2009).

Full author affiliations accompany this article online at go.nature.com/8d9vjx. 